\title{
Orthodontic Management of Early and Congenitally Missing Anterior Teeth - Case Reports
}

\author{
Kavitha Odathurai Marusamy ${ }^{1 *}$, Saravanan Ramasamy ${ }^{2}$, Narendra Basutkar ${ }^{2}$ \\ and Ahmed Hussein Al Kaf ${ }^{3}$ \\ 'Assistant Professor, Department of Preventive Dentistry, Ibn Sina National College,Jeddah - 22421, \\ Saudi Arabia; dr.omkavitha@gmail.com \\ ${ }^{2}$ Assistant Professor, Department of Oral \& Maxillofacial Rehabilitation, Ibn Sina National College, \\ Jeddah - 22421, Saudi Arabia; docnaren28feb@ibnsina.edu.sa \\ ${ }^{3}$ Lecturer, Department of Oral \& Maxillofacial Rehabilitation, Ibn Sina National College, Jeddah- \\ 22421, Saudi Arabia; ahk3000@hotmail.com
}

\begin{abstract}
Abstrac
Early loss or congenitally missing anterior teeth pose unique challenges for orthodontists. Maxillary arch restricted development may lead to narrow upper arch, drifting of adjacent teeth and creates midline shift to the opposite side. There are many treatment options available to manage the missing anterior teeth which includes canine substitution by closing the space and reshaping the adjacent teeth, create a space for missing teeth and replace with a tooth supported restoration, or a single tooth dental implant. Auto-transplantation and removable partial dentures are other less common options. The paramount consideration of treatment plan should be conservation. This article discusses orthodontic management of different missing anterior teeth cases. Two case reports describe the substitution of adjacent tooth for missing anterior. Another case is about creating space for prosthetic restoration of missing anterior tooth. The factors which play important role while planning the treatment are discussed. Orthodontists frequently encounter patients with congenitally missing teeth. Generally, the treatment of choice should be the least invasive option that satisfies the expected esthetics and functional objectives.
\end{abstract}

Keywords: Congenitally Missing Teeth, Dental Substitution, Interdisciplinary Approach, Orthodontics,

\section{Introduction}

Orthodontic treatment needs in patients with congenitally missing anterior teeth is high because of facial aesthetics consideration. It can adversely affect an individual's selfesteem and may even provoke an unfavorable response from others in society ${ }^{1}$. Early loss of teeth restricts dental arch development that leads to a constricted arch, drifting of adjacent teeth, creates midline shift to the opposite side and gives a compromised smile. Congenital absence of one or both of the maxillary incisors in humans has been observed since the Paleolithic period. With the evolution of humans, the face and jaws tend to decrease in the anteroposterior direction. This trend can limit the space needed to accommodate all of the teeth consequently the last tooth of each series tends to disappear (third molars, second premolars and lateral incisors). This is a hereditary process. A generation that has an anomalous tooth (small sized maxillary lateral incisors/peg-shaped lateral incisors) will have descendants that no longer possess this tooth².

Agenesis can also be associated with other factors such as: congenital deformities (including ectodermal dysplasia), radiation and nutritional disorders. However,

${ }^{*}$ Author for correspondence 
genetics represents the primary etiological factor of tooth agenesis $^{3}$. In a previous study, congenital absence of the permanent lateral incisor with a frequency of $2.2 \%$ and absence of the second premolar with a frequency of 3.4\% were reported ${ }^{4}$. The tooth agenesis is usually bilaterally. There is an exception in relation to the upper lateral incisors, which often are absent unilaterally, and the left side is more affected than the right side $^{5}$. Management of congenital or early loss of maxillary and mandibular teeth has unique challenges in treatment planning and mechanotherapy for orthodontists, prosthodontists and general practitioners ${ }^{6}$.

Generally, space opening with tooth replacement and space closure with canine substitution options relies on several parameters to be considered. Occlusal relationship (i.e., overjet and overbite, molar relationship), facial typology and profile, arch length, and tooth size discrepancies are the important considerations. The morphology of the canine, size and shape, and its colour also may address different treatment strategies ${ }^{7}$. Dental and facial criteria must be evaluated before substituting the adjacent tooth as a treatment of choice for replacing missing teeth. They include malocclusion, amount of crowding, profile, size, shape and colour of substituted tooth ${ }^{8}$. Angle class II malocclusion with no crowding in the lower arch and Angle class I malocclusion with sufficient crowding that requires mandibular extraction are good candidates for tooth substitution. Evaluation of profile is mandatory. Well balanced and straight profile is ideal. A patient who has convex profile, retrusive mandible and deficient chin prominence may not be an appropriate individual for substitution of adjacent tooth. Shape, size and colour of the substituted tooth are important factors to be considered esthetic. The ideal canine substitute for a lateral incisor is one with a similar color and shade as the central incisor, with smaller dimensions both at the cementoenamel junction buccolingually and mesiodistally, and with a relatively flat labial surface and narrow mid-crown width buccolingually?.

Creating space for restoration can be the best treatment alternative for individuals who do not meet the qualifications necessary to be considered for substitution. The amount of space requirement needed is determined by esthetics of mesiodistal width between the anterior teeth. The width relationship between lateral and central incisors should follow the golden proportion. Onelateral incisor is equal to two-thirds of a central incisor ${ }^{10}$. Occlusion is the second factor that affects the amount of space that needs to be created. Achieving good intercuspation with a normal canine relationship, coinciding midlines, and optimal overbite and overjet relationship should provide adequate space for a prosthetic central or lateral incisor that is esthetically pleasing ${ }^{11}$.

Restorative options are single tooth implant, tooth supported restoration or auto-transplantation. The single tooth implant has become a popular method of replacing missing teeth ${ }^{12,13}$. However, there are still certain instances in which implants cannot be used, such as in the patient who is unwilling to undergo the necessary treatment to facilitate proper implant placement. When implants are part of the treatment plan, the amount of space that needs to be opened depends on the particular implant system. With implants as a restorative treatment option, treatment planning has become more complex for the dental practitioner, and an interdisciplinary team approach is recommended ${ }^{14-16}$. An interdisciplinary approach may involve pre-prosthetic orthodontic treatment. Orthodontic alignment will facilitate proper fixed prosthesis.

In this article, in-addition to describing the management of malocclusions resulting from congenitally missing maxillary lateral incisors, the management of missing central incisor due to early trauma also described.

\subsection{Case Report-1: Substitution of Lateral Incisor for Missing Central Incisor}

20-year-old female patient reported with early loss of 11 due to trauma 12 years back. On examination, she presented with Class I molar relationship. Intraorally proclined upper anteriors with an overjet of $6 \mathrm{~mm}$, missing 11 (Figure 1) with the available space of $5 \mathrm{~mm}$. Cephalometric analysis evidence of convex profile and within normal facial proportions (Figure 2). Treatment plan was to substitute the lateral incisor as central incisor.

Treatment progress: 0.22 slot MBT brackets were chosen. Central incisor bracket was placed on lateral incisor. Lateral incisor bracket to canine and canine bracket to first premolar were placed subsequently. 0.014 NiTi wire, followed by $0.018,0.16^{\star} 22$ and $18^{\star} 25 \mathrm{NiTi}$ wires were placed for leveling and aligning of the upper and lower arch. Then $19^{\star} 25$ stainless steel wire was placed to close the space with the help of power chain. Miniscrew anchorage was placed (Figure 3) in both upper and lower arch between the right canine and first premolar. Class I molar was converted to class II with the help of miniscrew by using class III elastics to lower miniscrew and power chain with upper miniscrew. After space closure the alginate impression was taken to do the wax up in tooth number 12 and 13 (Figure 4). 

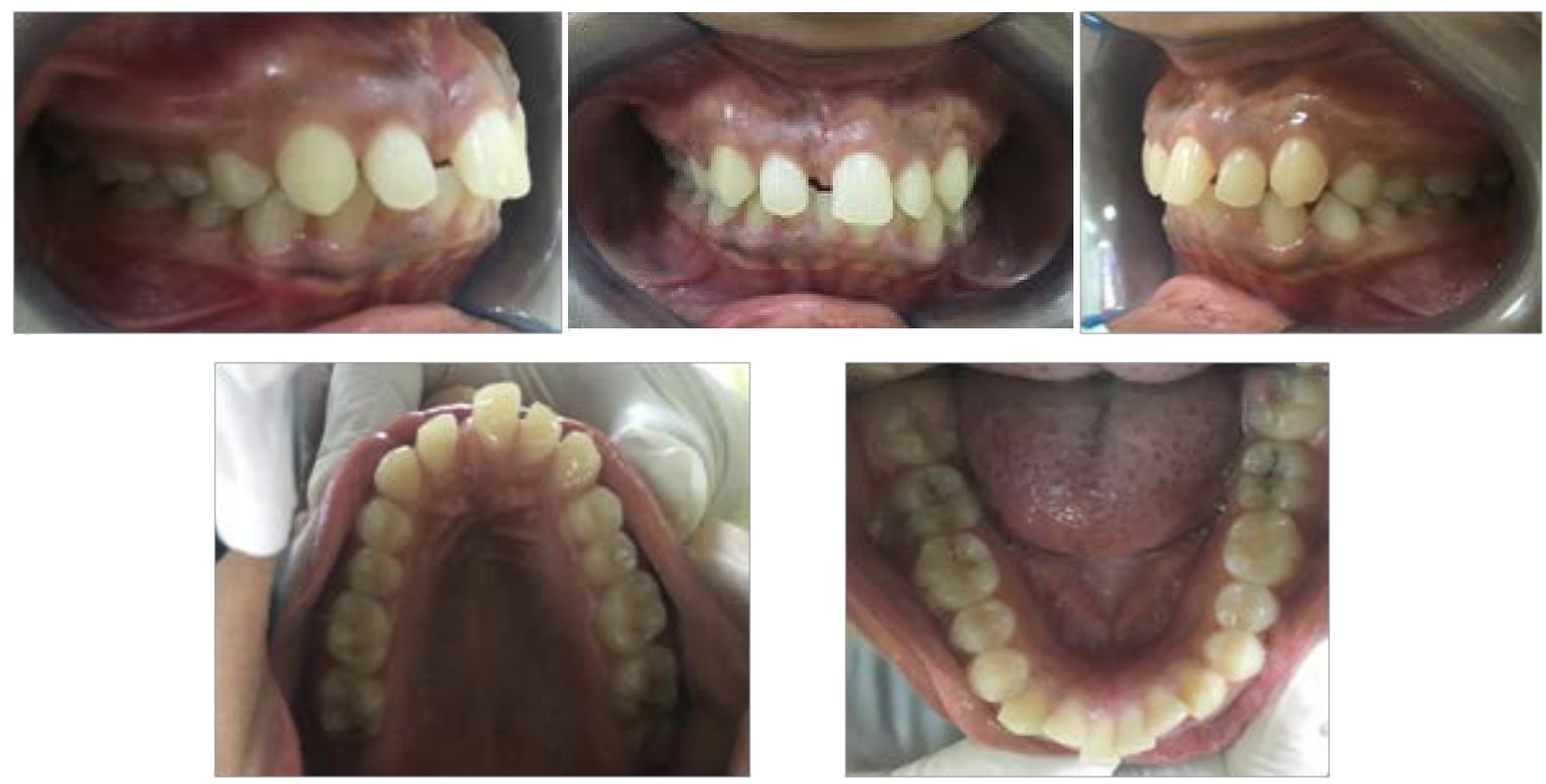

Figure 1. Pretreatment intraoral pictures.
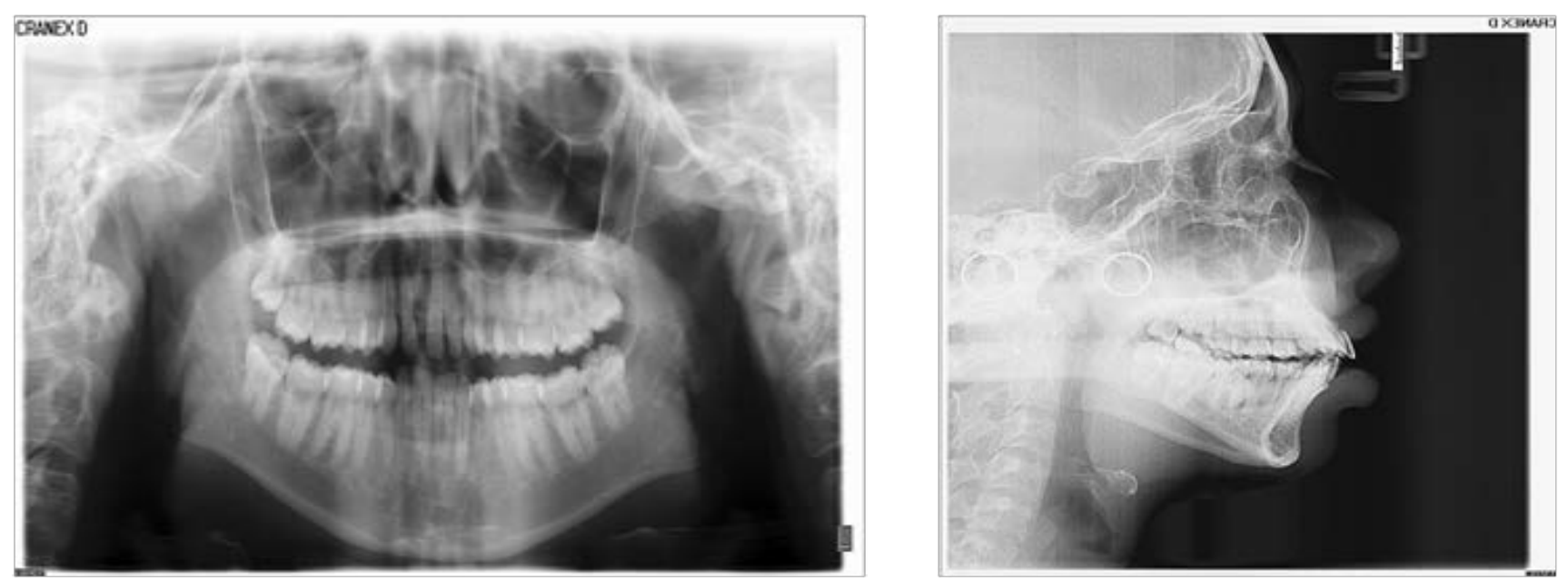

Figure 2. Pretreatment X Rays.
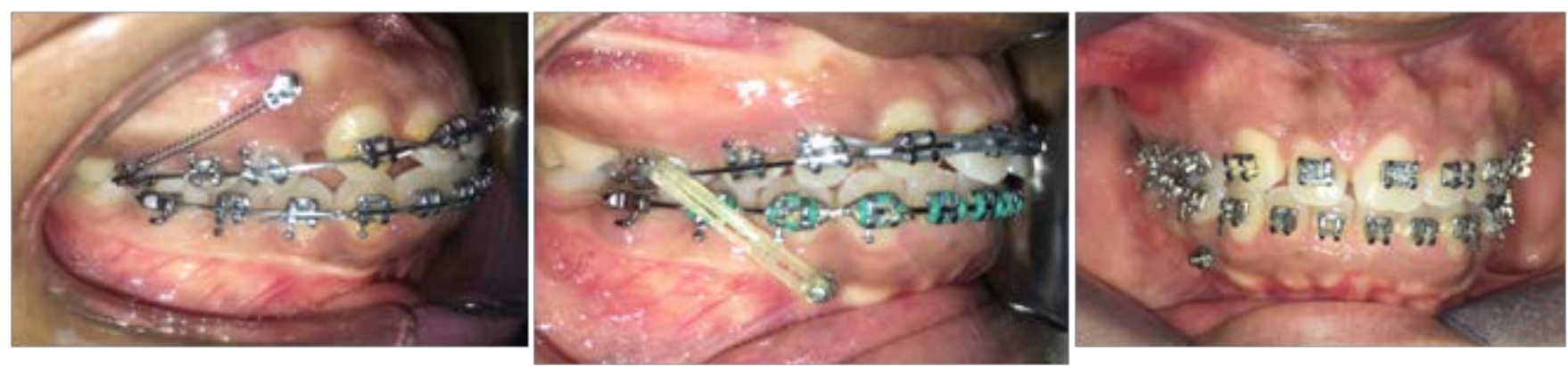

Figure 3. Space clocure and molar correction by miniscrews. 


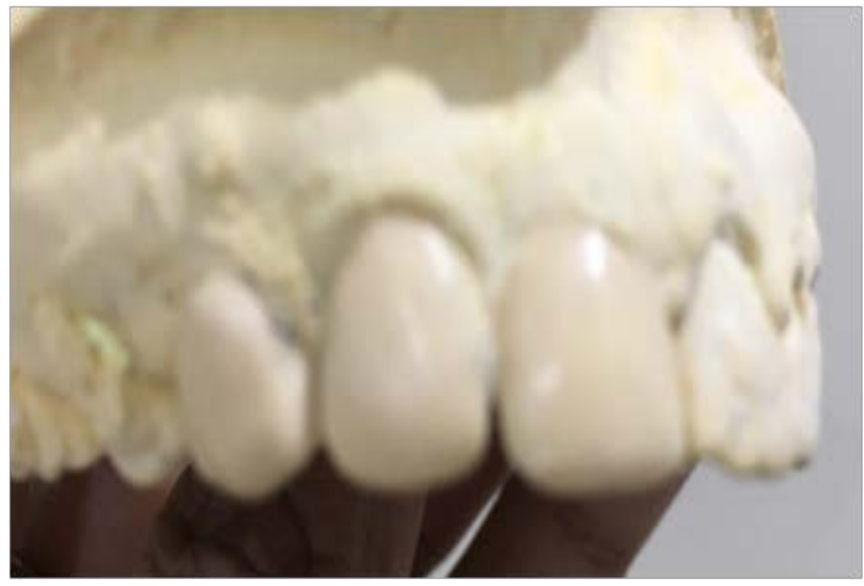

Figure 4. Wax setup for reshaping of lateral incisor and canine.
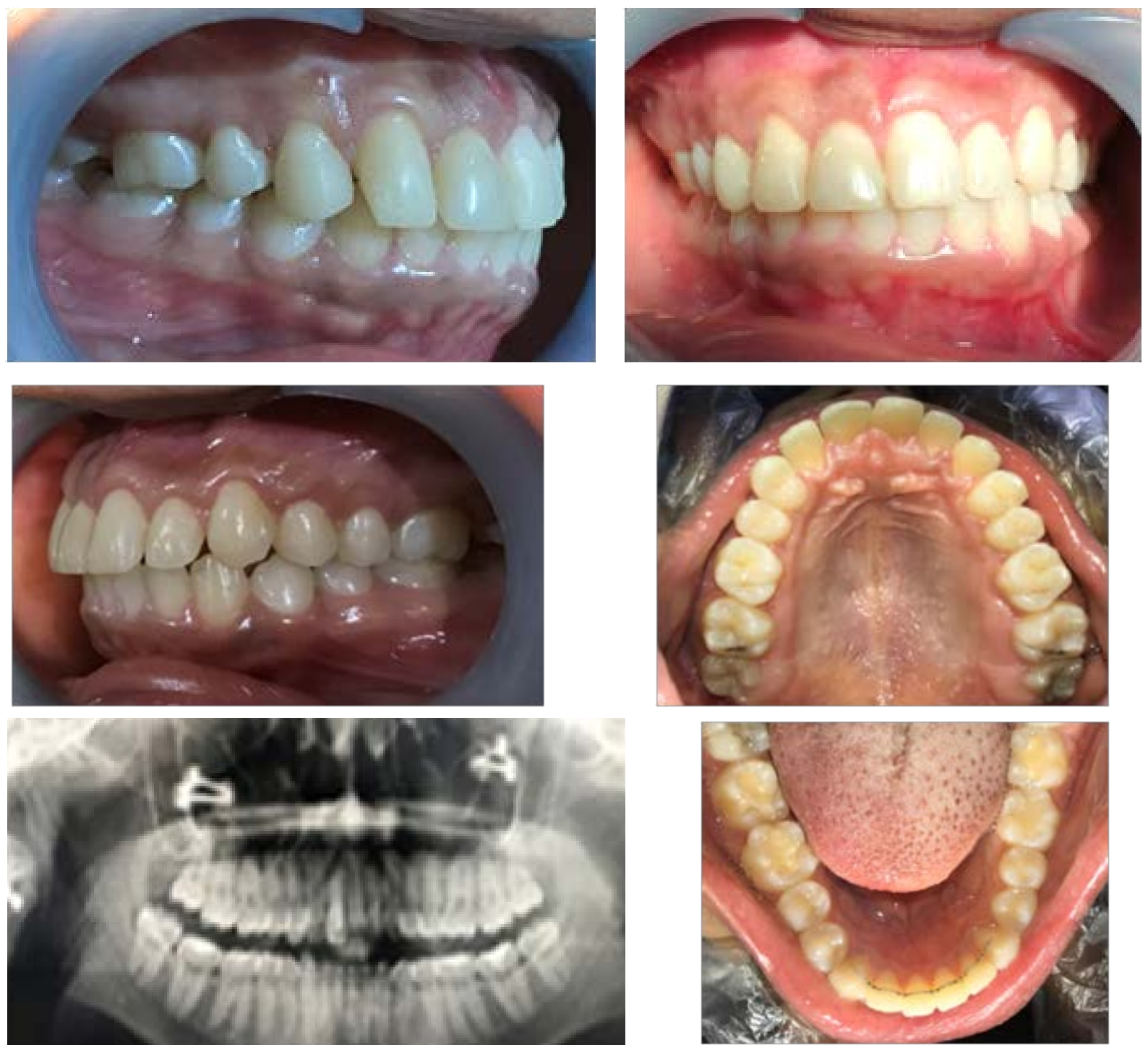

Figure 5. Post treatment pictures. 
Treatment results: Lateral incisor was successfully moved to central incisor place (Figure 5). Proclination was corrected compared with pretreatment cephalometric analysis. Composite buildup was done in right lateral incisor to get central incisor morphology. Enameloplasty in tooth 13 was done to have lateral incisor morphology. Periodontal surgery was done in tooth number 12 and 13 to improve the gingival margin.

\subsection{Case Report-2: Substitution of Canine for Missing Lateral Incisor}

18-year old female reported with congenitally missing upper left lateral incisor, while the right lateral incisor was a peg-shaped and midline shift of $2 \mathrm{~mm}$ to the left side was seen (Figure 6). The cephalometric evaluation highlighted with a class I skeletal relationship.

The treatment plan was to correct the deviated upper dental midline by extracting upper right peg lateral incisor and close the space of lateral incisors with bilateral canine substitution.

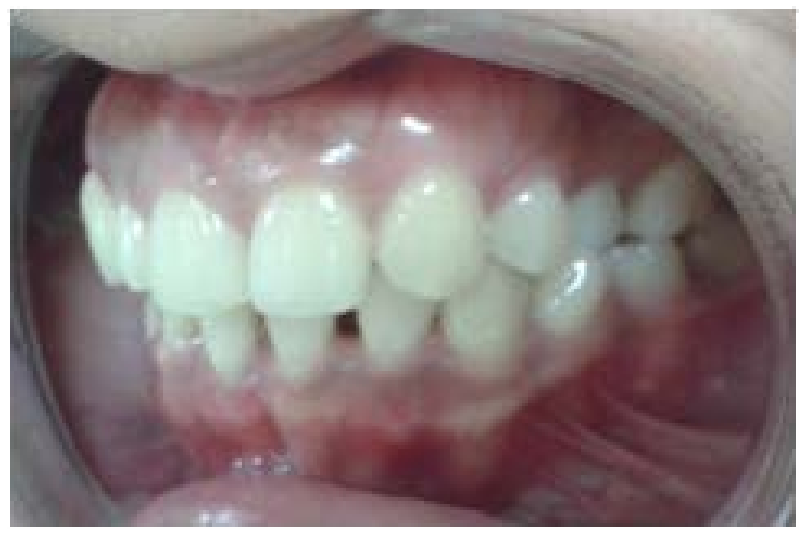

Treatment progress: A fixed multibracket appliance was placed to align, level, and manage spacing of both upper and lower dental arches. Ni-Ti archwire were preferred to increase patient compliance and reduce initial discomfort.

After starting orthodontic treatment arch aligning and leveling was done. Incremental enamel reduction was done in peg right lateral incisor (Figure 7), both mesially and distally in every appointment to avoid an unaesthetic appearance for the patient. Later, the peg lateral was extracted and orthodontic space closure done with sliding mechanics.

Treatment results: Midline correction was achieved by closing lateral incisor space. Canines were extruded and later recon toured the incisal edges to mimic laterals. Palatal cusp reduction was done in both first premolars to get canine guided occlusion. The gingival margin of the natural canine was positioned more incisally to the central incisor gingival margin to match the normal gingival position of lateral incisor (Figure 8).

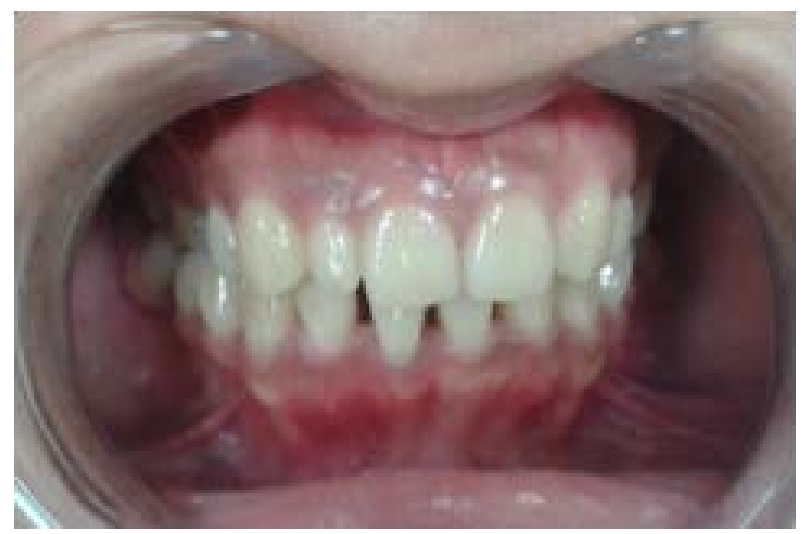

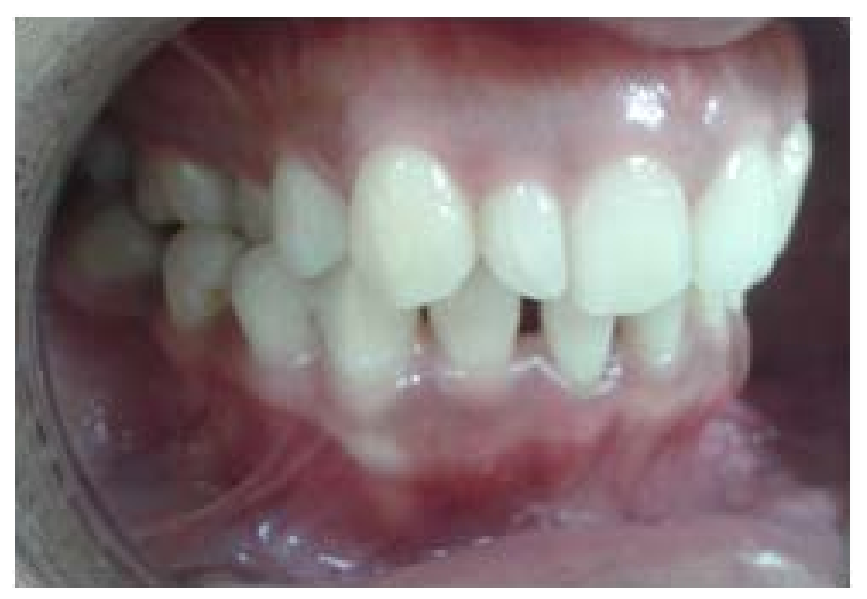

Figure 6. Pretreatment intraoral pictures. 


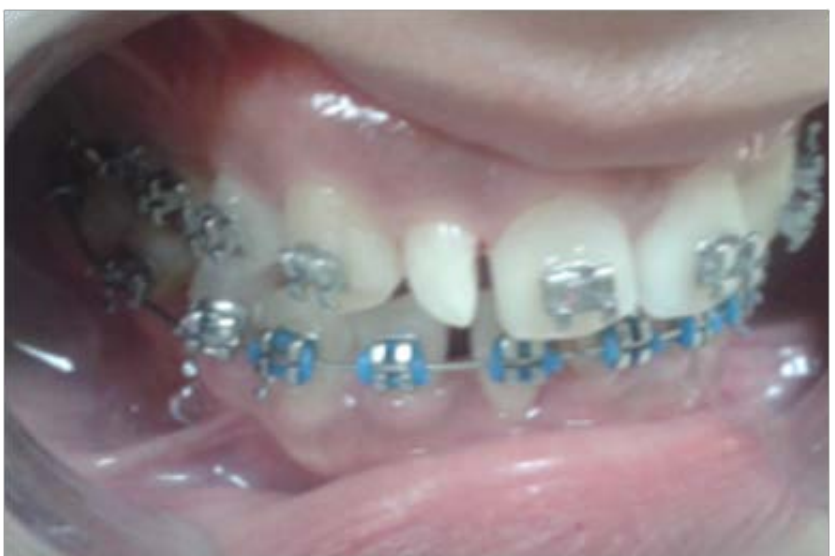

Figure 7. Treatment progress: incremental proximal stripping of peg lateral is done in Every visit during space closure.

\subsection{Case Report - 3: Create Space for Missing Central Incisor for Implant Restoration}

28-year-old male patient presented with complaints of missing anterior tooth. Due to early loss of right central incisor, the space was closed by midline drifting of left central incisor. Overbite and overjet were $1 \mathrm{~mm}$, having
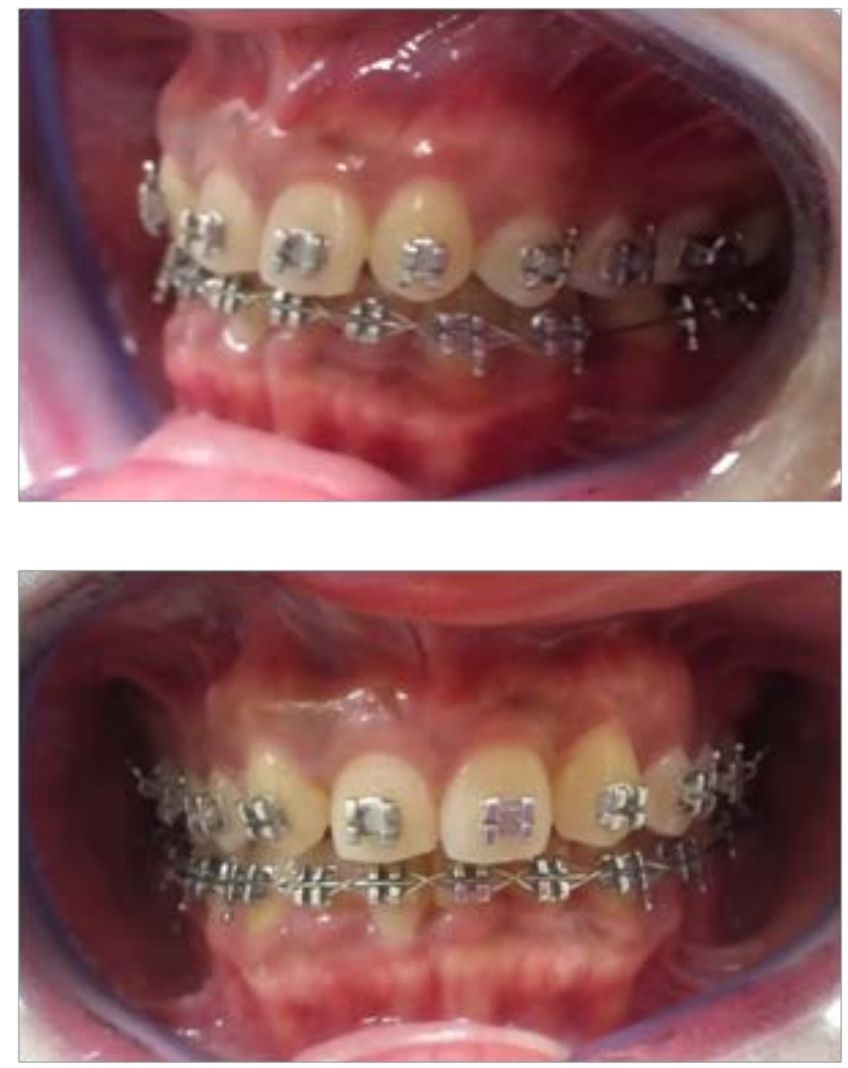

tendency of edge to edge bite due to collapse of the arch for early missing central incisor. The available central incisor space was $3 \mathrm{~mm}$, midline shift to the right by $5 \mathrm{~mm}$, maxillary arch was constricted and in cross bite due to early loss of maxillary central incisor. The treatment plan was to correct the midline shift by Miniscrew, to correct the crossbite by arch wire expansion, create the space for missing incisor tooth for implant restoration (Figure 9).

Treatment progress: After orthodontic bracket placement, the leveling and aligning was done by progressive NiTi wires. The cross bite was corrected by arch wire expansion. The orthodontic mini screw anchorage implant was placed at the left 2 nd premolar area. E tie was given from left side canine hook to Miniscrew to correct the midline. Along with $\mathrm{E}$ tie open coin spring was also given to create the space for missing tooth.

Treatment results: At the end of orthodontic treatment, $9 \mathrm{~mm}$ space was gained. Crossbite corrected. Also, root alignment adjacent teeth were done to achieve sufficient bone between the roots to place the implant (Figure 10). Finally an endosseous implant was placed and a matching prosthetic rehabilitation achieved with the help of implantologist (Figure 11).
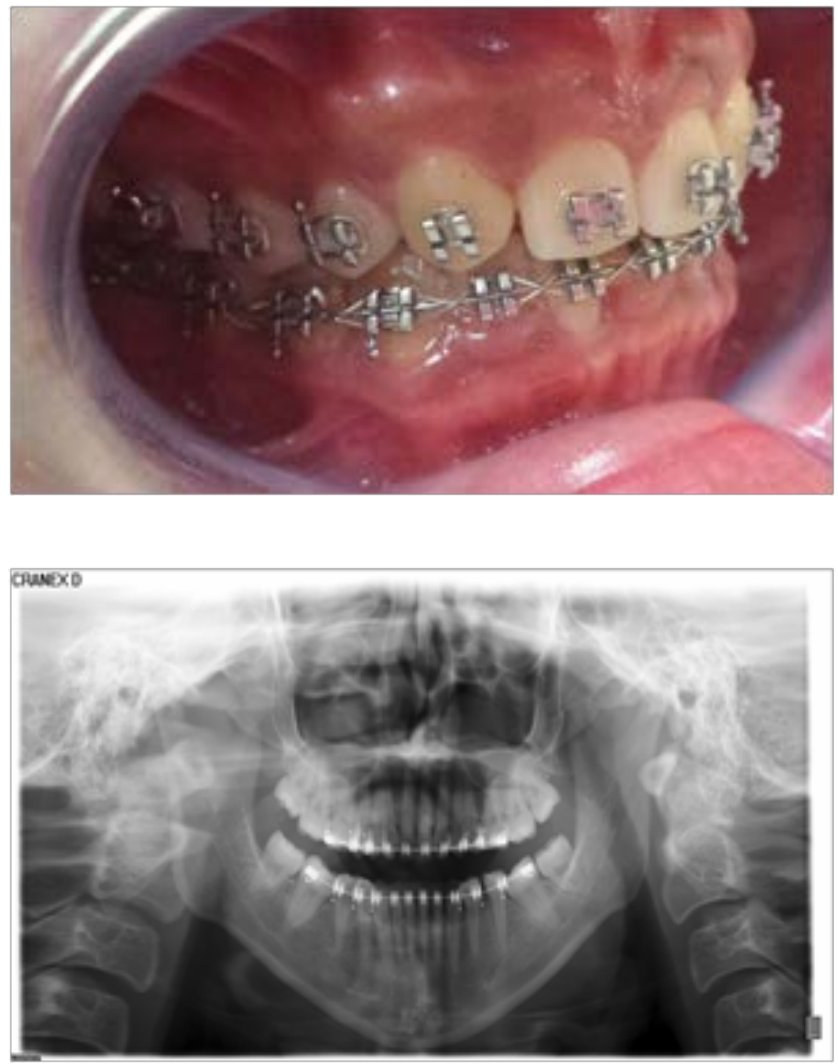

Figure 8. Treatment results: After subtitution of canine as lateral incisor. 

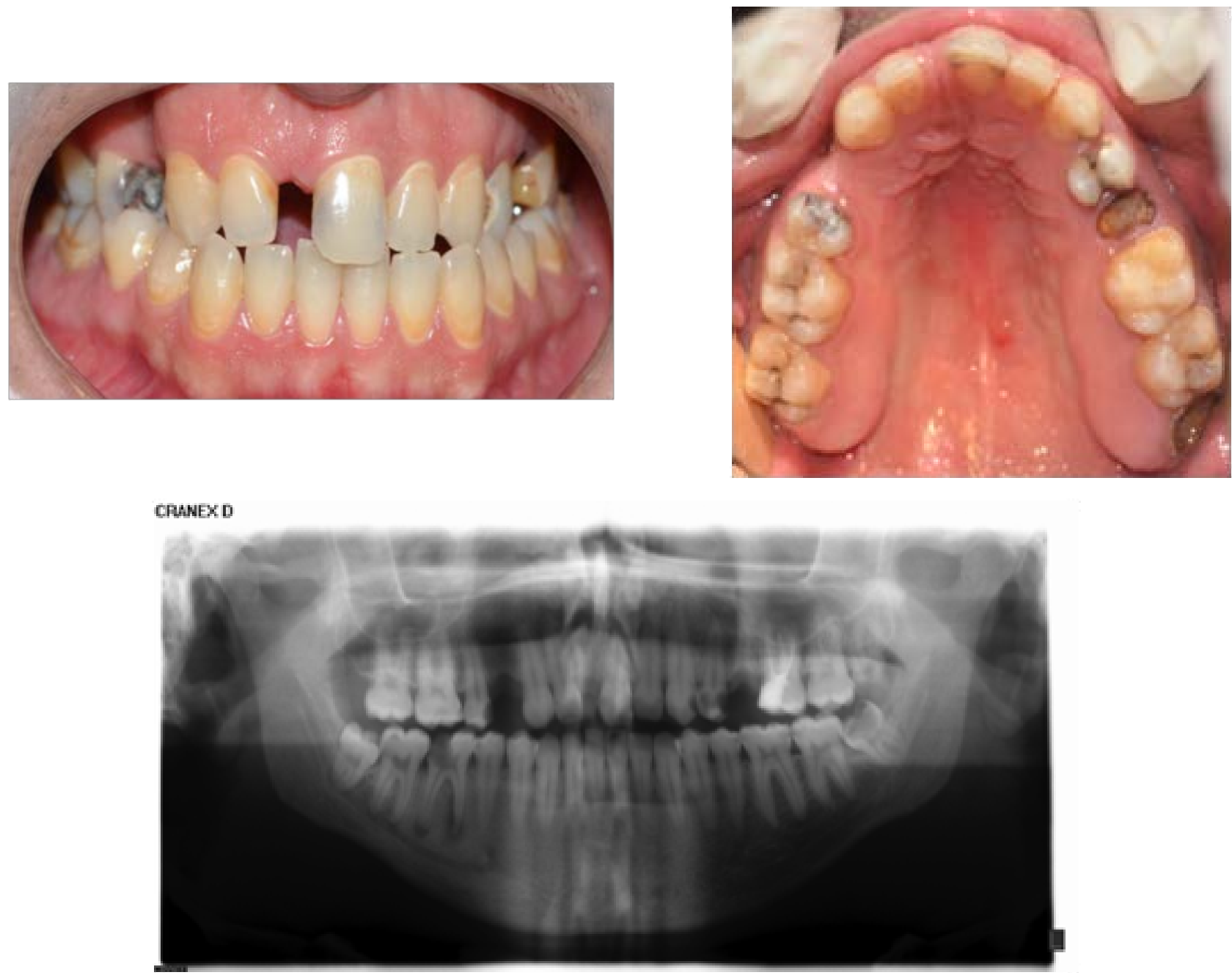

Figure 9. Pre-treatment intraoral pictures.
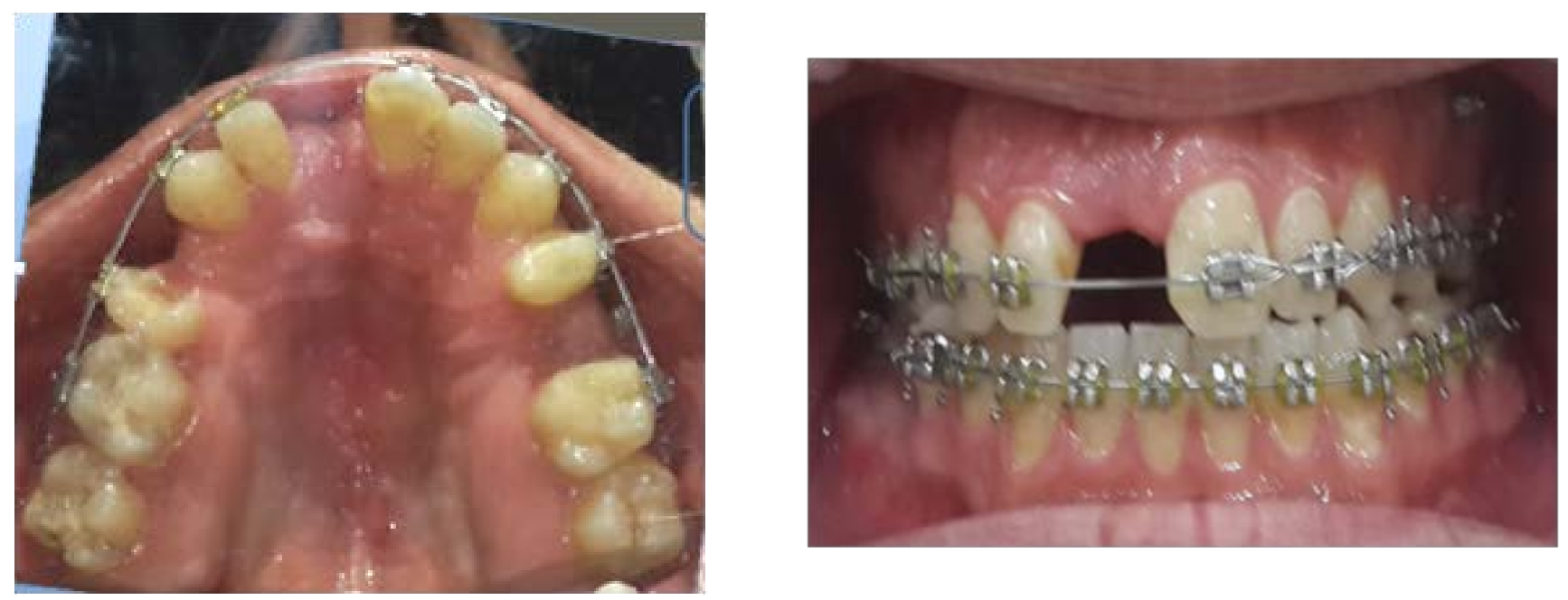

Figure 10. After space opening in 11 area. 

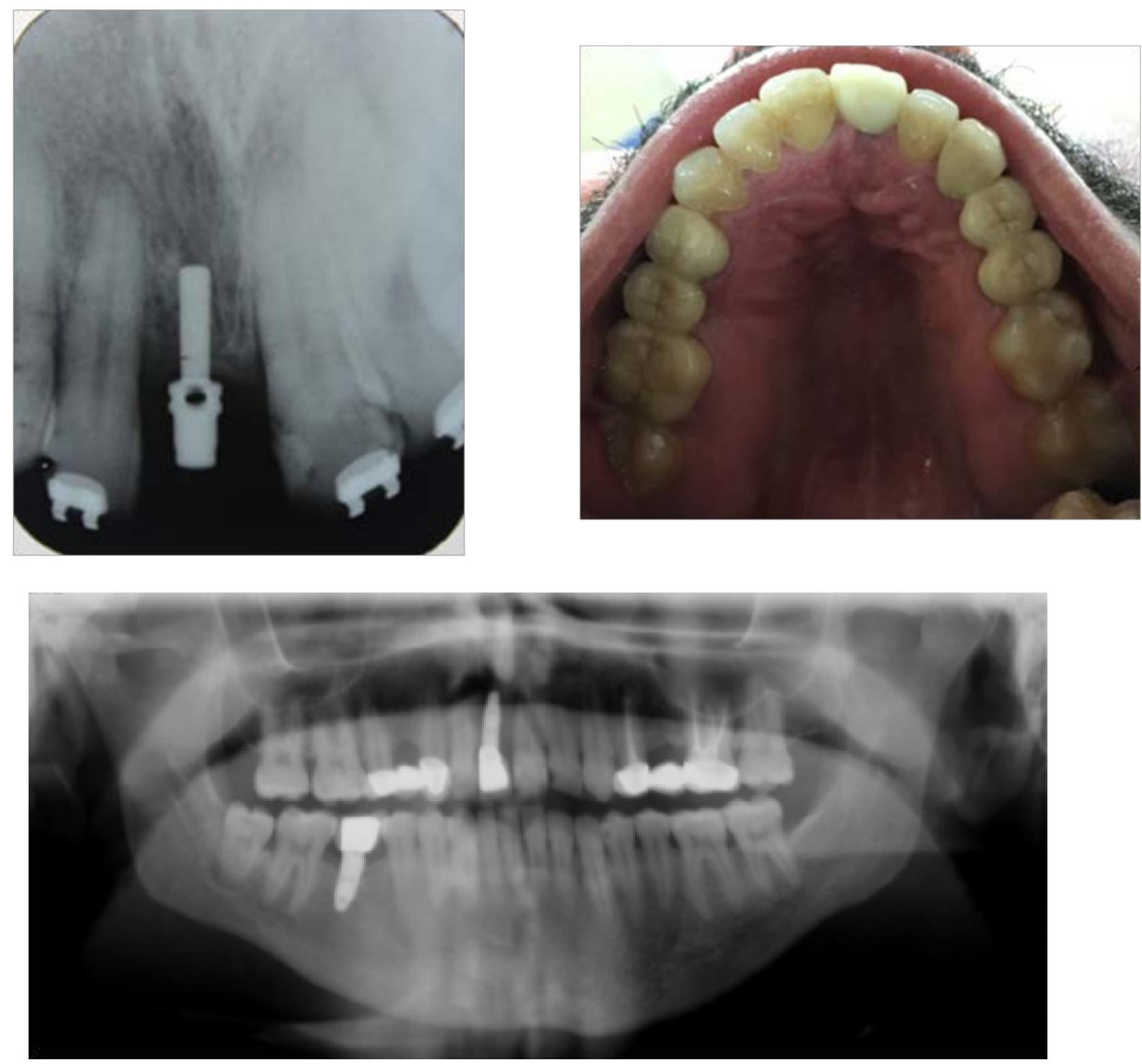

Figure 11. Post treatment pictutres: After implant placement.

\section{Discussion}

Managing patients with congenitally or early missing maxillary and mandibular teeth raises several important issues. Before going to the final treatment plan, there are many factors need to be taken into consideration which includes amount of space, patient's age, type of malocclusion and condition of adjacent teeth ${ }^{8}$. Generally, the least invasive option that satisfies the expected esthetic and functional objectives should be the main consideration.
In congenitally missing or peg-shaped lateral incisors early investigation will give the patient time to explore all possible treatment options. A full set of orthodontic records including radiographs, models and clinical photographs are recommended for the diagnosis of congenitally missing laterals and to planning substitution of adjacent teeth. A diagnostic set-up model is beneficial for planning of treatment and esthetics for patient motivation. Treatment plan was considering the profile, growth status, color and shape of the canines, if space closure with canine substitution was planned. 
In this current article, our cases regarding the management of missing unilateral incisors were successfully treated by substituting the canines and lateral incisors. This method is an excellent treatment option for replacing missing tooth. Adjacent tooth substitution allows the hard and soft tissue architecture to remain in a natural state, making it better suited to respond to the changes over time ${ }^{17}$. Closing spaces and replacing missing maxillary lateral incisors by using the canines is indicated in full-lip profiles when anterior teeth are severely protruded or tipped labially. In such cases, opening spaces for the missing lateral incisors will make anterior teeth protrude even more, thus worsening the patient's profile and compromising the long-term stability of the end result. If the patient has a balanced profile with normally inclined anterior teeth and minimal or no space available in the maxillary arch, orthodontic space closure is indicated. Whenever teeth in the mandibular arch need to be extracted for orthodontic reasons - such as severe crowding or protrusion - orthodontic space closure by using canines to replace missing lateral incisors is indicated in the maxillary $\operatorname{arch}^{18}$. Post orthodontically few factors need to be checked. Some clinical procedures may improve the orthodontic results in cases of missing maxillary incisors. It includes: 1 . mesiodistal positioning and angulation of mesially moved substituted tooth, 2 . intrusion of the lateral incisor and extrusion of the canine to achieve optimal alveolar bone height and gingival contours, 3. recontouring of the canine cusp, 4 . mesial rotation of the first premolar, and 5. gingivectomy on the lateral incisor to increase clinical crown height ${ }^{19}$. Substituted teeth gingival margin, colour, size and shape for optimal esthetic and functional results in orthodontic space closure, canines need to be transformed to better resemble and function as lateral incisors ${ }^{20}$. The gingival margin of the natural canine should be positioned incisal to the central incisor gingival margin. This helps camouflage the substituted canine. Occasionally, a gingivectomy may need to be performed to properly position the marginal gingiva. If the gingival level of the canine initially is apical, it will have to be extruded orthodontically, and extensive cusp-tip trimming will be necessary ${ }^{21}$. Reducing canine width through proximal grinding also should be performed. First premolars should be extruded relative to the adjacent teeth to simulate canines. Grinding of the palatal cusps also is recommended to avoid interferences during lateral movements ${ }^{22}$.
Regarding to create space for missing maxillary central incisor, there are three ways to determine the required space for missing teeth. Golden proportion, use contralateral tooth size and Bolton's analysis ${ }^{23}$. Ideally, maxillary lateral incisor should be about two-third the width of the central incisor. The most predictable guide for determining ideal spacing is to construct a diagnostic wax up. This simplifies treatment for the orthodontist and restorative dentist. Patients with accentuated dentoalveolar protrusions and soft-tissue convexity are not good candidates for such procedures ${ }^{24}$. However, if upright maxillary incisors need to be protruded, or tipped labially, to help correct anterior crossbites or to gain upper lip support - such as in patients with constricted arch, orthodontic space opening for one or both missing central and lateral incisors is indicated even if minimal or no space is available in the maxillary arch. Teeth adjacent to the missing lateral incisor space should have parallel roots, if endosseous implants are considered for prosthetic rehabilitation. The main disadvantage of orthodontic space opening is that the patient needs a permanent prosthesis in an area of the mouth in which tooth shade, gingival contour and margins are critical and not always easy to control ${ }^{25}$. An implant on maxillary incisors produced similar, well accepted and satisfactory esthetic results ${ }^{26}$.

\section{References}

1. Hobkirk JA, Goodman JR, Jones SP. Presenting complaints and findings in a group of patients attending a hypodontia clinic. Br. Dent. J. 1994 Nov; 177(9):337-39. https://doi.org/10.1038/ sj.bdj.4808606. PMid: 7980981.

2. Mattheeuws N, Dermaut L, Martens G. Has hypodontia increased in Caucasians during the 20th century? A meta-analysis. Eur. J. Orthod. 2004 Feb 1; 26(1):99-103. https:// doi.org/10.1093/ejo/26.1.99. PMid: 14994889.

3. Mossey PA. The heritability of malocclusion: Part 2. The influence of genetics in malocclusion. Br. J. Ortho. 1999; 26(3):195-201. https://doi.org/10.1093/ortho/26.3.195. PMid: 10532158.

4. Symons AL, Stritzel F, Stamation J. Anomalies associated with hypodontia of the permanent lateral incisor and second premolar. J. Clin. Pediat. Dent. 1993; 17:109-11.

5. Romano R, Bichacho N, Touati B, editors. The Art of the Smile: Integrating Prosthodontics, Orthodontics, Periodontics, Dental Technology, and Plastic Surgery in Esthetic Dental Treatment. Quintessence Publishing Company; 2005. 
6. Biggerstaff RH. The orthodontic management of congenitally absent maxillary lateral incisors and second premolars: A case report. Am. J. Orthod. Dentofacial. Orthop. 1992; 102(6):53745. https://doi.org/10.1016/0889-5406(92)70071-H.

7. Paduano S, Cioffi I, Rongo R, Cupo A, Bucci R, Valletta R. Orthodontic management of congenitally missing maxillary lateral incisors: A case report. Case Rep. Dent. 2014. https:// doi.org/10.1155/2014/731074. PMid: 24711929, PMCid: PMC3970084.

8. Kokich VO, Jr., Kinzer GA. Managing congenitally missing lateral incisors. Part I: Canine substitution. J. Esthet. Restor. Dent, 2005; 17(1):5-10. https://doi.org/10.1111/j.1708-8240.2005. tb00076.x. PMid: 15934680.

9. Rosa M, Zachrisson BU. Integrating esthetic dentistry and space closure in patients with missing maxillary lateral incisors. J. Clin. Orthod. 2001; 35(4) 221-34.

10. Levin EI. Dental esthetics and the golden proportion. J. Prosthet. Dent. 1978; 40(3):244-52. https://doi.org/10.1016/00223913(78)90028-8.

11. Fields HW Jr. Orthodontic-restorative treatment of relative mandibular anterior excess tooth size problems. Am. J. Orthod. 1981; 79(2):176-83. https://doi.org/10.1016/00029416(81)90315-8.

12. Mayer TM, Hawley CE, et al. The single tooth implant: A viable alternative for single tooth replacement. J. Periodontol. 2002; 73(7):687-93. https://doi.org/10.1902/jop.2002.73.7.687. PMid: 12146526.

13. Naert I, Koutsikakis G, Duyck J, et al. Biologic outcome of single-implant restorations as tooth replacements: A long term follow up study. Clin. Implant. Dent. Relat. Res. 2000; 2(4):20918. https://doi.org/10.1111/j.1708-8208.2000.tb00119.x. PMid: 11359280.

14. Tuverson DL. Orthodontic treatment using canines in place of missing maxillary lateral incisors. Am. J. Orthod. 1970; 58(2):109-27. https://doi.org/10.1016/0002-9416(70)90065-5.

15. McNeill RW, Joondeph DR. Congenitally absent maxillary lateral incisors: Treatment planning considerations. Angle. Orthod. 1973; 43:24-29.
16. Roth PM, Gerling JA, Alexander RG. Congenitally missing lateral incisor treatment. J. Clin. Orthod. 1985; 19:258-62.

17. Zachrisson B, Rosa M, Toreskog S. Congenitally missing maxillary lateral incisors: Canine substitution. Am. J. Orthod. Dentofacial Orthop. 2011; 139:434-45. https://doi.org/10.1016/j. ajodo.2011.02.003. PMid: 21457853.

18. Sabri R. Management of missing maxillary lateral incisors. J. Am. Dent. Assoc. 1999 Jan 1; 130(1):80-84. https://doi.org/10.14219/ jada.archive.1999.0032. PMid: 9919035.

19. Grimm S, Frazão P, Antunes JL, Castellanos RA, Narvai PC. Dental injury among Brazilian schoolchildren in the state of São Paulo. Dent. Traumatol. 2004 Jun; 20(3):134-38. https://doi. org/10.1111/j.1600-4469.2004.00238.x. PMid:15144443.

20. Yankelson M. Altering canines to resemble lateral incisors: A new technique. J. Int. Assoc. Dent. Child. 1973; 4(2):39-40.

21. Martin M. Possibilités thérapeutiques les cas dagénésie d'incisives latérales supérieures. Revue d'Orthopédie DentoFaciale. 1992 Mar 1; 26(1):87-97. https://doi.org/10.1051/ odf/1992003.

22. Argyropoulos E, Payne G. Techniques for improving orthodontic results in the treatment of missing maxillary lateral incisors a case report with literature review. Am. J. Orthod. Dentofacial Orthop. 1988 Aug 1; 94(2):150-65. https://doi. org/10.1016/0889-5406(88)90363-0.

23. Spear F, Mathews D, Kokich VG: Interdisciplinary management of single-tooth implants. Semin Orthod. 1997; 3:45-72. https:// doi.org/10.1016/S1073-8746(97)80039-4.

24. McNeill RW, Joondeph DR. Congenitally absent maxillary lateral incisors: Treatment planning considerations. Angle. Orthod. 1973; 43:24-29.

25. Tuverson DL. Orthodontic treatment using canines in place of missing maxillary lateral incisors. Am. J. Orthod. 1970; 58(2):109-27. https://doi.org/10.1016/0002-9416(70)90065-5.

26. Jamilian A, Perillo L, Rosa M. Missing upper incisors: A retrospective study of orthodontic space closure versus implant. Prog. Orthod. 2015 Dec 1; 16(1):2. https://doi.org/10.1186/ s40510-015-0072-2. PMid: 25769117, PMCid: PMC4385022. 